GRASAS Y ACEITES 69 (3)

July-September 2018, e268

ISSN-L: 0017-3495

https://doi.org/10.3989/gya.0225181

\title{
cis-trans isomerization of unsaturated fatty acids in edible oils to prepare trans fat
}

\author{
W. Liu ${ }^{凶}$ and G.H. Lu \\ Lipid Chemistry, College of Food Science and Technology, Henan University of Technology, \\ Lianhua Street 100, Zhengzhou 450001, P. R. China \\ ${ }^{\square}$ Corresponding author: liuwei307@hotmail.com; liuwei820307@126.com
}

Submitted: 16 February 2018; Accepted: 09 May 2018

SUMMARY: Trans fats, unsaturated fatty acids with at least one double bond in the trans configuration, have received a great amount of attention in the field of oleo chemistry and safety. In this work, the cis-trans isomerization of unsaturated fatty acids in edible oils has been successfully developed using simple and cheap $p$-toluenesulfinic acid as catalyst. The effects of reaction time, temperature, catalyst loading, and the amounts of water and antioxidants on the cis-trans isomerization have been systematically investigated. The results indicate that the amount of water (0-20 wt \%) and antioxidants $(0-200 \mathrm{mg} / \mathrm{kg})$ had no significant effect on this cis-trans isomerization of unsaturated fatty acids in edible oils. The final products (trans fats) from the cis-trans isomerization reaction were characterized by both GC and React IR. The yield of trans double bonds from the isomerized fat can reach $79.6 \%$ after heating at $100{ }^{\circ} \mathrm{C}$ for $90 \mathrm{~min}$ without changing either the location of the double bonds or the degree of unsaturation. In addition, this convenient method has been applied to various vegetable oils (e.g., olive oil, camellia seed oil, corn oil, sesame oil, sunflower oil and soybean oil) and nearly $80.0 \%$ yields of TFA were generated, which shows a promising method to provide trans-fat products for research related to oleo and food chemistry.

KEYWORDS: cis-trans Isomerization; Edible fat; p-Toluenesulfinic acid; trans Fats; trans Fatty acids

RESUMEN: Isomerización cis-trans de ácidos grasos insaturados en aceites comestibles para preparar grasas trans. Las grasas trans, ácidos grasos insaturados con al menos un doble enlace en la configuración trans, han recibido muchas atenciones en oleoquímica y seguridad. En este trabajo, se ha llevado a cabo con éxito la isomerización cis-trans de ácidos grasos insaturados en aceites comestibles usando mediante un método simple y barato utilizando ácido $p$-toluenosulfínico como catalizador. Los efectos del tiempo de reacción, la temperatura, la carga del catalizador, la cantidad de agua y los antioxidantes en la isomerización cis-trans se han investigado sistemáticamente. Los resultados indicaron que la cantidad de agua ( $0-20 \%$ en peso) y antioxidante (0-200 $\mathrm{mg} /$ $\mathrm{kg}$ ) no tuvo un efecto significativo sobre la isomerización cis-trans. Los productos finales (grasas trans) de la reacción de isomerización cis-trans se caracterizaron por GC y React IR. El rendimiento en dobles enlaces trans de la manteca isomerizada puede alcanzar el $79,6 \%$ tras calentar a $100{ }^{\circ} \mathrm{C}$ durante 90 minutos sin cambiar tanto la posición de los dobles enlaces como el grado de insaturación. Además, este método tan útil se ha aplicado a diferentes aceites vegetales (por ejemplo, oliva, semilla de camelia, maíz, sésamo, girasol y soja) y casi se forma alrededor del $80.0 \%$ de ácidos grasos trans, lo que demuestra ser un método prometedor para proporcionar productos grasos trans para investigaciones relacionadas en la química del aceite y los alimentos.

PALABRAS CLAVE: Ácido p-toluenosulfínico; Ácidos grasos trans; Grasas trans; Isomerización cis-trans; Manteca comestible

ORCID ID: Liu W https://orcid.org/0000-0003-1706-1208, Lu GH https://orcid.org/0000-0002-7586-7448

Citation/Cómo citar este artículo: Liu W, Lu GH. 2018. cis-trans isomerization of unsaturated fatty acids in edible oils to prepare trans fat. Grasas Aceites 69 (3), e268. https://doi.org/10.3989/gya.0225181

Copyright: (C2018 CSIC. This is an open-access article distributed under the terms of the Creative Commons Attribution 4.0 International (CC BY 4.0) License. 


\section{INTRODUCTION}

It is a known fact that fatty acids, which contain saturated fatty acids and unsaturated fatty acids, are one of the most important components of edible oils (Kurt, 2018). The cis-trans isomerization of unsaturated fatty acids in edible oils is not expected in most cases because an excessive intake of trans fatty acids (TFAs) has been associated with the increased risk of coronary heart disease (CHD), sudden death, diabetes mellitus and increased markers for systematic inflammation (Duffy et al., 2006; Hulshof et al., 1999; Lemaitre et al., 2006). Edible oils consist of triacylglycerides as their main components ( $>95 \%)$, which differ in their fatty acid compositions to a certain extent (Belitz et al., 1999). Most of the natural unsaturated fatty acids in edible oils are non-conjugated acids with a cis structure. Meanwhile, natural TFAs account for only a very small fraction of natural unsaturated fatty acids.

In terms of chemical structure, TFAs are unsaturated fatty acids with trans-non-conjugated carbon-carbon double bonds. Natural TFAs are produced by the bio-hydrogenate unsaturated fatty acids of the feeds in the rumen of ruminants and occur naturally in ruminant meat (beef, lamb and goat) and dairy products at up to about $5 \%$ of the total fatty acids (Katherinem et al., 2010; Kuhnt et al., 2015; Trattner et al., 2015; Vahmani et al., 2016). In addition to natural TFAs, TFAs are mainly produced during the industrial processing of oils (e.g., vegetable oils). For example, TFAs are produced from cis-unsaturated fatty acids during the heating of oils at high temperatures $\left(>200{ }^{\circ} \mathrm{C}\right)$ and the hydrogenation process in the presence of hydrogen and metal-catalysts (e.g., Ni, Cu) (Liu et al., 2017). Hydrogenated vegetable oils have been widely used in the food industry for a long period of time to produce different oil-based foods, such as cakes, cookies, french fries and margarine, because of their longer shelf-life, oxidative stability and other particular physical properties (Cizmeci et al., 2005; García et al., 2017; Iida et al., 2015; Mozaffarian et al., 2006). For example, soybean oil was hydrogenated using Nysosel 222 nickel-based catalysts under constant conditions $\left(165^{\circ} \mathrm{C}, 2\right.$ bar hydrogen pressure) and the total TFAs were up to $40.5 \%$ after $100 \mathrm{~min}$ of the hydrogenation process (Kala et al., 2012). The structure of TFAs is more stable than cis fatty acids against thermodynamics. In the process of refining and deodorization of vegetable oils, the oils are usually heated to $250{ }^{\circ} \mathrm{C}$ for a long period of time (15-120 $\mathrm{min})$ to eliminate odor components (Li et al., 2012). Furthermore, the deep frying process $\left(160-180^{\circ} \mathrm{C}\right)$ using unsaturated vegetable oils (e.g., soybean oil, sunflower oil, canola oil) would also lead to an increase in trans fatty acids when the operation time was more than 20 h (Farag et al., 2010; Tsuzuki et al., 2010).
Due to the potential risk related to TFAs in food, extensive research has been focused on finding a convenient method for a high conversion of the cistrans isomerization of long-chain unsaturated fatty acids for lipid analysis and other scientific proposes (Ferreri et al., 2001; Geißler et al., 2003; Tzeng et al., 2014). Many types of catalysts, such as nitrous acid and selenium, have been developed for the synthesis of the trans fatty acids through a corresponding cistrans isomerization reaction (Snyder et al., 1982). However, these catalysts had some disadvantages, such as toxicity, higher reaction temperature, side reactions and production of impurities, etc. There are reports that $p$-toluenesulfinic acid is an ideal catalyst with the advantages of being fast and efficient to accomplish the cis-trans isomerization of pure unsaturated fatty acids methyl esters (Gibson et al., 1976). Up to now, reports on a fast and efficient method to promote the cis-trans isomerization of fatty acids in edible oils to prepare trans lipids are rare due to the fact that lipids are more complicated than pure fatty acid methyl esters, and the minor components in lipids will have an unfavorable effect on the cis-trans isomerization of fatty acids to prepare trans fats (Akin et al., 2018; Elbadawi et al., 2017).

In this paper, the cis-trans isomerization of unsaturated fatty acids in edible oils has been successfully performed to prepare trans lipids using $p$-toluenesulfinic acid as catalyst. The unsaturation and location of the carbon-carbon double bonds of the fatty acids remain unchanged with this simple method. With this simple method, prepared trans lipids can be applied in food chemistry research and used as lipid research standards.

\section{EXPERIMENTAL PROCEDURES}

\subsection{Materials}

Edible fat (I.V.=54 $\mathrm{g} \mathrm{I}_{2} / 100 \mathrm{~g}$ ) was purchased from Jiuyuan Oils \& Fats Co., Ltd. (Tianjin, China). Olive oil (I.V. $=80 \mathrm{~g} \mathrm{I}_{2} / 100 \mathrm{~g}$ ) was purchased from Sinograin Oils Co., Ltd. (Tianjin, China). Sunflower oil 1\# (I.V.=131 g I $/ 2 / 100 \mathrm{~g}$ ) was purchased from Sinograin Oils Co., Ltd. (Tianjin, China). Sunflower oil 2\# (I.V.=132 $\mathrm{g} \mathrm{I}_{2} / 100 \mathrm{~g}$ ) was purchased from Standard Food Co., Ltd. (Shanghai, China). Camellia seed oil (I.V. $=85 \mathrm{~g} \mathrm{I}_{2} / 100 \mathrm{~g}$ ) was purchased from COFCO Co., Ltd. (Xinjiang, China). Corn oil (I.V.=120 g $\mathrm{I}_{2} / 100 \mathrm{~g}$ ) was purchased from Xiwang Food Co., Ltd. (Shandong, China). Soybean oil 1\# (I.V.=127 g $\mathrm{I}_{2} / 100 \mathrm{~g}$ ) and soybean oil 2\# (I.V.=128 g $\left.\mathrm{I}_{2} / 100 \mathrm{~g}\right)$ were purchased from Jiusan group soybean Technology Co., Ltd. (Tianjin, China) and Wilmar International Limited, respectively. Sesame oil (I.V.=107 g $\mathrm{I}_{2} / 100 \mathrm{~g}$ ) was obtained from a local market. Petroleum ether $\left(99 \%, 60-90{ }^{\circ} \mathrm{C}\right)$ was obtained from Precision Chemical Reagent Factory 
(Tianjin, China). Sodium sulfate anhydrous (> $99 \%$ ), methanol (HPLC grade) and $n$-hexane (HPLC grade) were purchased from Kemiou Chemical Reagent Co., Ltd. (Tianjin, China). Sodium $(>99.5 \%$ ) was obtained from Kelong Chemical Reagent Factory (Chengdu, China). 1,4-dioxane (99\%) was acquired from Fuyu Fine Chemical Co., Ltd. (Tianjin, China). Hydrochloric acid $(99 \%)$ was obtained from Chemical Reagent Factory (Luoyang, China). Sodium hydroxide $(99 \%)$ was obtained from Yongda Chemical Reagent Co., Ltd. (Tianjin, China). Butyl-hydroxyanisol (BHA, 98\%), butyl-hydroxytoluene (BHT, > 99\%), $t$-butyl-hydroquinone (TBHQ, 98\%) and sodium p-toluenesulfinate (anhydrous, 98\%) were obtained from Aladdin Bio-Chem Tenchnology Co., Ltd. (Shanghai, China). All materials were used as received without further treatment.

\subsection{Catalyst preparation}

$p$-Toluenesulfinic acid was prepared by the acidification of sodium $p$-toluenesulfinate (Snyder et al., 1982). Sodium $p$-toluenesulfinate was dissolved in a small amount of water and $p$-toluenesulfinic acid was precipitated by the addition of the calculated amount of $6 \mathrm{~mol} / \mathrm{L}$ hydrochloric acid $(\mathrm{HCl})$ to this solution. The precipitated acid was filtered off and washed rapidly several times with ice-cold distilled water. Finally, $p$-toluenesulfinic acid was thoroughly dried for $24 \mathrm{~h}$ at $40{ }^{\circ} \mathrm{C}$ under vacuum.

\subsection{Preparation process for trans-lipids}

In the cis-trans isomerization experiments, 250 $\mathrm{mg}$ edible fat, $10 \mathrm{~mL} \mathrm{1,4-dioxane} \mathrm{and} \mathrm{a} \mathrm{certain}$ amount of $p$-toluenesulfinic acid were added to the reactor and the resulting mixture was heated for a certain period of time under a nitrogen atmosphere. After cooling to room temperature, the solution was diluted with $25 \mathrm{~mL}$ of a $1 \mathrm{~mol} / \mathrm{L} \mathrm{NaOH}$ solution and then extracted with petroleum ether. The obtained organic layer was washed three times with a saturated sodium chloride solution and then the solvent was removed by a rotary evaporator under vacuum, which afforded the desired trans-lipid product.

\subsection{Characterization methods}

The isomerized fat was treated by methyl esterification before the gas chromatography analysis. In detail, 2-3 drops of isomerized fat and 2 $\mathrm{mL}$ of $n$-hexane were mixed in a glass tube, and then $3 \mathrm{~mL}$ of $0.5 \mathrm{~mol} / \mathrm{L}$ sodium methylate were added into the tube. The mixture was rigorously vibrated for 5-7 min and the mixture was then centrifuged to obtain the supernatant. The supernatant was dried by sodium sulfate anhydrous prior to the gas chromatography analysis. Analysis of the isomerized fat was performed on a Agilent Technologies $6890 \mathrm{~N}$ gas chromatography (GC) using a $30.0 \mathrm{~m} \times 250$ $\mu \mathrm{m} \times 0.25 \mu \mathrm{m}$ BPX-70 capillary column and detected using a flame ionization detector (FID). The carrier was nitrogen with a flow of $1.0 \mathrm{~mL} / \mathrm{min}$. The oven was programmed from the set temperature of $170{ }^{\circ} \mathrm{C}$ to $210^{\circ} \mathrm{C}$ at $2{ }^{\circ} \mathrm{C} / \mathrm{min}$. Injection volumes were $1 \mu \mathrm{L}$ with the inlet set to split mode and the split ratio was 50:1. The GC injection temperature was $250{ }^{\circ} \mathrm{C}$ and the detector temperature was $300{ }^{\circ} \mathrm{C}$. The yield of trans double bonds in the isomerized oil samples was calculated from the capillary GC data. Furthermore, the experimental results were mainly determined by the yield of total trans double bonds. The yield of total trans double bonds was calculated using Eq. (1):

$$
\begin{aligned}
& \text { Yield of total trans double } \\
& \text { bonds }(\%)=\frac{\text { Total trans double bonds }}{\text { Total double bonds }} \times 100 \%
\end{aligned}
$$

Where total trans double bonds are the double bonds of the elaidic acid, trans linoleic acid and trans linolenic acid; total double bonds are the double bonds of the oleic acid, linoleic acid and linolenic acid.

\section{RESULTS AND DISCUSSION}

\subsection{General consideration}

The proposed mechanism for trans carboncarbon double bond formation in edible oils using $p$-toluenesulfinic acid as catalyst is presented in Scheme 1. According to the previously proposed mechanism (Gibson et al., 1976), the $p$-toluenesulfinic acid catalyst would produce an arylthiyl radical when $p$-toluenesulfinic acid was heated in the reaction system. All of the radicals would promote cis-trans isomerization. Hence, the reaction heating temperature and antioxidant compounds in edible oils would both affect the isomerization reaction.

As we know, edible oils, mainly vegetable oils, contain natural antioxidants and synthetic antioxidants which would inhibit the lipid peroxidation and other radical reactions. Thus, edible oil without any antioxidants is an ideal candidate for the cis-trans isomerization reaction through a radical process. Therefore, edible fat

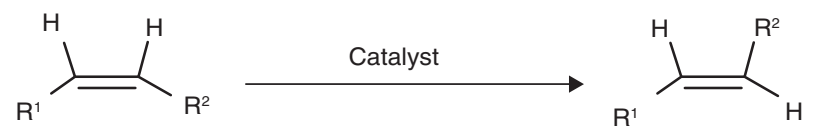

SCHEME 1. Reaction scheme for the cis-trans isomerization reaction in lipids. 
without any antioxidants was selected as the model lipid for the isomerization reaction because the content of natural antioxidants in edible fat is scarce. In addition, the fatty acid composition of the edible fat used in this work showed that the content of unsaturated fatty acids in edible fat is about $50.0 \%$, which includes $36.8 \%$ oleic acid and $13.1 \%$ linoleic acid. Refined edible fat was suitable to study this free radical-like cis-trans isomerization of unsaturated carbon-carbon double bonds of fatty acids to prepare trans-lipid.

\subsection{Effect of reaction time on the isomerization of the edible fat}

Firstly, the reaction time was one of the key factors for isomerization because the radical intermediates generated by the $p$-toluenesulfinic acid are responsible for the fat isomerization. The effect of reaction time on the isomerization of edible fat is shown in Table 1. The isomerization was performed at $120{ }^{\circ} \mathrm{C}$ under a nitrogen atmosphere using $p$-toluenesulfinic acid as catalyst (oil/ catalyst $=250: 20)$ to investigate the effect of reaction times $(10 \mathrm{~min}, 20 \mathrm{~min}, 30 \mathrm{~min}, 60 \mathrm{~min}, 90 \mathrm{~min}$ and $120 \mathrm{~min}$ ) on the isomerization process. Obviously, the generation of radical intermediates required a certain period of time and a much lower yield of TFAs $(2.8 \%)$ was generated after heating for only $10 \mathrm{~min}$. When the reaction time was increased to $20 \mathrm{~min}$, the yield of TFAs in the fat was increased rapidly and a $72.5 \%$ yield of TFAs was detected. Prolonging the reaction time (30-90 $\mathrm{min})$ led to a slight increment in TFA and a $79.2 \%$ yield of TFAs was produced in fat after heating for $90 \mathrm{~min}$. Continuing to increase the reaction time $(120 \mathrm{~min})$ resulted in no significant changes in the yield of trans double bonds. Therefore, an operation reaction time of $90 \mathrm{~min}$ was chosen in the following experiments.

TABLE 1. Effect of reaction time on the isomerization of edible fat

\begin{tabular}{lccc}
\hline \multirow{2}{*}{$\begin{array}{l}\text { Reaction } \\
\text { time }\end{array}$} & \multicolumn{2}{c}{ Final isomer composition (\%) } & Yield of total \\
\cline { 2 - 3 } & Elaidic acid & $\begin{array}{c}\text { Trans-linoleic } \\
\text { acid }\end{array}$ & $\begin{array}{c}\text { trans double } \\
\text { bonds (\%) }\end{array}$ \\
\hline $10 \mathrm{~min}$ & 3.0 & 2.3 & 2.8 \\
$20 \mathrm{~min}$ & 70.8 & 65.7 & $72.5 \pm 1.6$ \\
$30 \mathrm{~min}$ & 77.3 & 74.7 & $75.4 \pm 1.8$ \\
$60 \mathrm{~min}$ & 77.6 & 75.4 & $76.2 \pm 1.3$ \\
$90 \mathrm{~min}$ & 79.5 & 78.8 & $79.2 \pm 0.5$ \\
$120 \mathrm{~min}$ & 77.6 & 78.9 & $79.1 \pm 0.7$ \\
\hline
\end{tabular}

Each value in the table represents the mean and mean \pm standard deviation of triplicate analyses, respectively. Reaction conditions: reaction temperature $120{ }^{\circ} \mathrm{C}$, ratio of edible fat to catalyst was 250 to $20(\mathrm{w} / \mathrm{w}), \mathrm{N}_{2}$.

\subsection{Effect of reaction temperature on the isomerization of edible fat}

The effect of reaction temperature on the isomerization of edible fat was investigated and shown in Table 2. The experiments were performed under a nitrogen atmosphere using $p$-toluenesulfinic acid (250:20 edible fat to catalyst) as catalyst to investigate the effect of different reaction temperatures $\left(60{ }^{\circ} \mathrm{C}, 80{ }^{\circ} \mathrm{C}, 100{ }^{\circ} \mathrm{C}, 120{ }^{\circ} \mathrm{C}\right.$ and $140^{\circ} \mathrm{C}$ ) on the isomerization process. Based on the reaction mechanism, the generation of the free radical catalyst from $p$-toluenesulfinic acid required a definite temperature.

It could be observed in the results that no generation of trans double bonds was observed when the reaction was performed below $100{ }^{\circ} \mathrm{C}\left(60{ }^{\circ} \mathrm{C}\right.$ and $80{ }^{\circ} \mathrm{C}$ ). When the experiment was carried out at $100{ }^{\circ} \mathrm{C}$ for $90 \mathrm{~min}$, the yield of trans double bonds in the fat could reach $79.6 \%$. Further increasing the reaction temperature $\left(120-140{ }^{\circ} \mathrm{C}\right)$ had almost no effect on the yield of trans double bonds in the fat. This is probably because the temperature was not the rate-determining step in this cis-trans isomerization reaction. In other words, it was impossible to increase the yield of trans double bonds through increasing the reaction temperature. Therefore, $100{ }^{\circ} \mathrm{C}$ was chosen as the optimum reaction temperature.

\subsection{Effect of amount of catalyst on the isomerization of the edible fat}

The catalyst amount had a certain impact on the cis-trans isomerization of the edible fat. The effect of the amount of catalyst in terms of different fat/ catalyst mass ratios $(250: 5,250: 10,250: 20$ and 250:40) was also investigated and the results are listed in Table 3 . Heating the fat at $100{ }^{\circ} \mathrm{C}$ without any catalyst did not lead to any production of TFAs after heating for $90 \mathrm{~min}$. The use of less catalyst (250:5) was not conducive to the production of transfat. The ratio of 250:20 led to a higher conversion

TABLE 2. Effect of reaction temperature on the isomerization of edible fat

\begin{tabular}{lccc}
\hline \multirow{2}{*}{$\begin{array}{l}\text { Reaction } \\
\text { temperature }\end{array}$} & \multicolumn{2}{c}{ Final isomer composition (\%) } & Yield of total \\
\cline { 2 - 3 } & Elaidic & $\begin{array}{c}\text { Trans-linoleic } \\
\text { acid }\end{array}$ & $\begin{array}{c}\text { trans double } \\
\text { bonds (\%) }\end{array}$ \\
\hline $60{ }^{\circ} \mathrm{C}$ & $/$ & $/$ & $/$ \\
$80{ }^{\circ} \mathrm{C}$ & $/$ & $/$ & $/$ \\
$100{ }^{\circ} \mathrm{C}$ & 79.7 & 79.3 & $79.6 \pm 0.2$ \\
$120{ }^{\circ} \mathrm{C}$ & 79.5 & 78.8 & $79.2 \pm 0.5$ \\
$140{ }^{\circ} \mathrm{C}$ & 78.7 & 78.1 & $78.4 \pm 0.1$ \\
\hline
\end{tabular}

Each value in the table represents the mean and mean \pm standard deviation of triplicate analyses, respectively. Reaction conditions: reaction time $90 \mathrm{~min}$, ratio of edible fat to catalyst was 250 to $20(\mathrm{w} / \mathrm{w}), \mathrm{N}_{2}$. 
TABLE 3. Effect of amount of catalyst on the isomerization of edible fat

\begin{tabular}{|c|c|c|c|}
\hline \multirow{2}{*}{$\begin{array}{l}\text { Ratio of edible } \\
\text { fat and catalyst } \\
\text { (w/w) }\end{array}$} & \multicolumn{2}{|c|}{ Final isomer composition (\%) } & \multirow{2}{*}{$\begin{array}{c}\text { Yield of total } \\
\text { trans double } \\
\text { bonds (\%) }\end{array}$} \\
\hline & $\begin{array}{l}\text { Elaidic } \\
\text { acid }\end{array}$ & $\begin{array}{c}\text { Trans-linoleic } \\
\text { acid }\end{array}$ & \\
\hline $250: 0$ & 0 & 0 & 0 \\
\hline $250: 5$ & 31.5 & 30.4 & 31.9 \\
\hline $250: 10$ & 60.4 & 58.0 & $59.3 \pm 0.8$ \\
\hline $250: 20$ & 79.7 & 79.3 & $79.6 \pm 0.2$ \\
\hline $250: 40$ & 79.9 & 80.0 & $80.0 \pm 2.6$ \\
\hline
\end{tabular}

Each value in the table represents the mean and mean \pm standard deviation of triplicate analyses, respectively. Reaction conditions: reaction temperature $100{ }^{\circ} \mathrm{C}$, reaction time $90 \mathrm{~min}, \mathrm{~N}_{2}$.

of TFAs $(79.6 \%)$ in the fat. Further increasing the catalyst amount (250:40) showed no improvement in the yield of trans double bonds in the fat product. Therefore, 250:20 was selected as the optimum mass ratio of fat and catalyst.

\subsection{Effect of water on the isomerization of the edible fat}

Water exists widely in oil-based food and has some impact on the reactions in food. The effect of water addition on the cis-trans isomerization of edible fat is shown in Table 4. It was evident that water addition ranging from $5-20 \%$ had no significant impact on the cis-trans isomerization of the edible fat. The total trans double bonds remained at the same level with increasing the amount of water. Because the small amount of added water probably evaporated into the gaseous state under heating $\left(100{ }^{\circ} \mathrm{C}\right)$ conditions, this resulted in separating it from the reaction system. These results made this method more convenient to produce trans-lipids without extra drying or dehydration of the oil sample before the isomerization reaction.
TABLE 4. Effect of water on the isomerization of edible fat

\begin{tabular}{|c|c|c|c|}
\hline \multirow[b]{2}{*}{$\begin{array}{l}\text { Water } \\
\text { addition }\end{array}$} & \multicolumn{2}{|c|}{ Final isomer composition (\%) } & \multirow{2}{*}{$\begin{array}{l}\text { Yield of total } \\
\text { trans double } \\
\text { bonds }(\%)\end{array}$} \\
\hline & $\begin{array}{c}\text { Elaidic } \\
\text { acid }\end{array}$ & Trans-linoleic acid & \\
\hline 0 & 79.7 & 79.3 & $79.6 \pm 0.2$ \\
\hline $5 \%$ & 79.9 & 79.8 & $79.9 \pm 0.4$ \\
\hline $10 \%$ & 79.9 & 80.5 & $80.2 \pm 0.1$ \\
\hline $20 \%$ & 79.8 & 79.5 & $79.7 \pm 0.6$ \\
\hline
\end{tabular}

Each value in the table represents the mean and mean \pm standard deviation of triplicate analyses, respectively. Reaction conditions: reaction temperature $100{ }^{\circ} \mathrm{C}$, reaction time $90 \mathrm{~min}$, ratio of edible fat to catalyst was 250 to 20 (w/w), $\mathrm{N}_{2}$. The added water was the weight percentage of the edible fat.

\subsection{Effect of antioxidant on the isomerization of the edible fat}

The cis-trans isomerization of carbon-carbon double bonds in edible fat was caused by free radicals. During the reaction, $p$-toluenesulfinic acid cleaved thermally to radicals which resulted in the production of trans fat. Hence, the antioxidant as free radical quencher would affect the radical reaction. Considering the complexity of natural antioxidants in different edible oils, various commonly used synthetic antioxidants are investigated in the cis-trans isomerization of carbon-carbon double bonds in edible fat. BHA (butyl-hydroxyanisol), BHT (butyl-hydroxytoluene) and TBHQ ( $t$-butyl-hydroxyquinone) are the most commonly used synthetic antioxidants for delaying the lipid oxidation process. Table 5 shows the effect of different antioxidants on the isomerization of edible fat. The results indicate that introducing $50-200 \mathrm{mg} / \mathrm{kg}$ BHA in the reaction system had no significant impact on the isomerization of the edible fat. However, the addition of $200 \mathrm{mg} / \mathrm{kg}$ BHT completely inhibited the isomerization of edible fat at $100{ }^{\circ} \mathrm{C}$ and no TFA was detected. Increasing the

TABLE 5. Effect of antioxidant on the isomerization of edible fat

\begin{tabular}{|c|c|c|c|c|}
\hline \multirow[b]{2}{*}{ Antioxidant content } & \multicolumn{2}{|c|}{ Final isomer composition (\%) } & \multirow{2}{*}{$\begin{array}{c}\text { Yield of total trans } \\
\text { double bonds }(\%)\end{array}$} & \multirow[b]{2}{*}{ Reaction temperature } \\
\hline & Elaidic acid & Trans-linoleic acid & & \\
\hline 0 & 79.7 & 79.3 & $79.6 \pm 1.0$ & $100^{\circ} \mathrm{C}$ \\
\hline $50 \mathrm{mg} / \mathrm{kg}$ BHA & 79.9 & 82.5 & $81.2 \pm 0.8$ & $100{ }^{\circ} \mathrm{C}$ \\
\hline $100 \mathrm{mg} / \mathrm{kg} \mathrm{BHA}$ & 79.8 & 82.0 & $80.7 \pm 0.7$ & $100{ }^{\circ} \mathrm{C}$ \\
\hline $200 \mathrm{mg} / \mathrm{kg}$ BHA & 79.8 & 82.9 & $81.4 \pm 1.2$ & $100{ }^{\circ} \mathrm{C}$ \\
\hline 200 mg/kg BHT & I & I & I & $100{ }^{\circ} \mathrm{C}$ \\
\hline $200 \mathrm{mg} / \mathrm{kg} \mathrm{BHT}$ & 79.4 & 79.2 & $79.3 \pm 0.4$ & $120^{\circ} \mathrm{C}$ \\
\hline $200 \mathrm{mg} / \mathrm{kg}$ TBHQ & 79.8 & 83.3 & $81.1 \pm 1.3$ & $100^{\circ} \mathrm{C}$ \\
\hline
\end{tabular}

Each value in the table represents the mean and mean \pm standard deviation of triplicate analyses, respectively. Abbreviations: BHA, butyl-hydroxyanisol; BHT, butyl-hydroxytoluene; TBHQ, $t$-butyl-hydroquinone. Reaction conditions: reaction time 90 min, ratio of edible fat to catalyst was 250 to $20(\mathrm{w} / \mathrm{w}), \mathrm{N}_{2}$. 
reaction temperature from $100{ }^{\circ} \mathrm{C}$ to $120{ }^{\circ} \mathrm{C}$, the cistrans isomerization took place smoothly with the addition of $200 \mathrm{mg} / \mathrm{kg}$ BHT and afforded the TFAs a yield of $79.3 \%$. Because the high radical inhibition activity of BHT was most likely obtained at $100{ }^{\circ} \mathrm{C}$, the isomerization of edible fat with BHT could be implemented by elevating the reaction temperature to $120{ }^{\circ} \mathrm{C}$. Moreover, introducing $200 \mathrm{mg} / \mathrm{kg}$ TBHQ into the reaction system had no significant impact on the isomerization of edible fat at $100{ }^{\circ} \mathrm{C}$. Therefore, cis-trans isomerization at $100{ }^{\circ} \mathrm{C}$ or $120{ }^{\circ} \mathrm{C}$ could efficiently take place in edible fat containing no more than $200 \mathrm{mg} / \mathrm{kg}$ synthetic antioxidants.

\subsection{Analysis of the isomerized fat by GC and FT-IR}

The results of cis-trans isomerized unsaturated fatty acids in edible fat monitored by GC are shown in Figure 1. The A and B diagrams in Figure 1 show the fatty acid compositions by GC before and after the cis-trans isomerization, respectively. It was clear that trans double bonds were formed. The results were achieved under the optimum conditions which were conducted at $100{ }^{\circ} \mathrm{C}$ for $90 \mathrm{~min}$. The fatty acid composition of isomerized edible fat (Table 6) showed that the yields of isomerized double bonds of oleic acid and linoleic acid were 79.7\% and 79.3\%, respectively. The total yield of trans double bonds in the final fat was $79.6 \%$ without a change in the location of the double bonds (Snyder et al., 1982).

IR spectroscopy is one of the most efficient tools to directly determine trans-double bonds. Therefore, the cis-trans isomerization of edible fat was also detected by React IR ${ }^{\mathrm{TM}}$ spectroscopy. The React IR ${ }^{\mathrm{TM}}$ spectra (Figure 2) clearly showed the generation of trans-double bonds. The new bonds, associated with trans fat formation, were observed

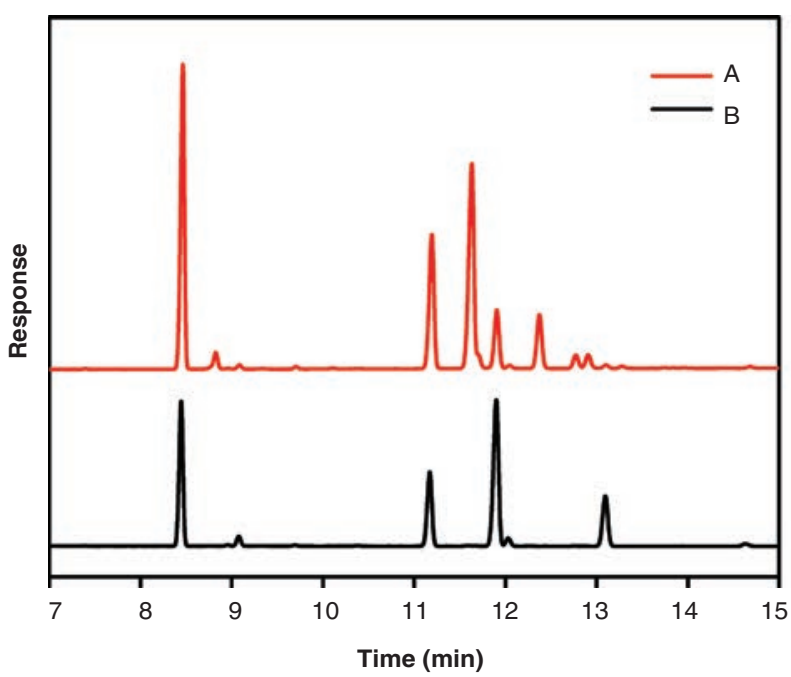

FiguRE 1. Gas chromatogram after (A) and before (B) the cis-trans isomerization of fat
TABLE 6. Fatty acid composition of the isomerized edible fat

\begin{tabular}{lc}
\hline Fatty acid & Content (\%) \\
\hline $\mathrm{C} 16: 0$ & 27.96 \\
$\mathrm{C} 18: 0$ & 17.40 \\
$\mathrm{C} 18: 1 \mathrm{t}^{\mathrm{a}}$ & 29.80 \\
$\mathrm{C} 18: 1 \mathrm{c}^{\mathrm{b}}$ & 7.58 \\
$\mathrm{C} 18: 2 \mathrm{t}, \mathrm{t}$ & 7.26 \\
$\mathrm{C} 18: 2 \mathrm{t}, \mathrm{c}$ & 1.84 \\
$\mathrm{C} 18: 2 \mathrm{c}, \mathrm{t}$ & 1.93 \\
$\mathrm{C} 18: 2 \mathrm{c}, \mathrm{c}$ & 0.50 \\
\hline
\end{tabular}

$\mathrm{at}=$ trans

${ }^{\mathrm{b}} \mathrm{c}=$ cis

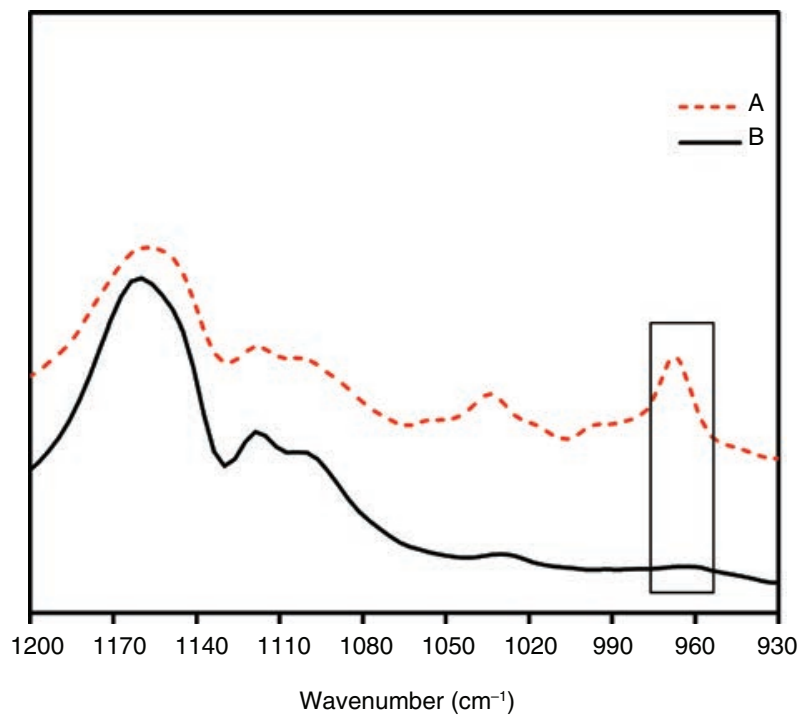

Figure 2. The FT-IR after (A) and before (B) the cis-trans isomerization of fat

at a bond of $966 \mathrm{~cm}^{-1}$. These results indicated that the cis-trans isomerization of edible fat was realized. Moreover, React IR was also used to monitor the cis-trans isomerization of fat process (Figure 3 ), and the trans fat was generated rapidly.

\subsection{Isomerization of different edible oils}

Based on the above results in hand, we investigated the cis-trans isomerization of unsaturated fatty acids in other edible oils, mainly vegetable oils (Table 7). It could be seen that the yields of trans double bonds in the eight kinds of isomerized edible oils were all close to $80.0 \%$. This is similar to an earlier report employing pure fatty acids as substrates (Snyder et al., 1982). In fact, vegetable oils contain various natural antioxidants with different kinds and concentrations, which are more complicated than edible fat or pure fatty acids. The yields of elaidic 


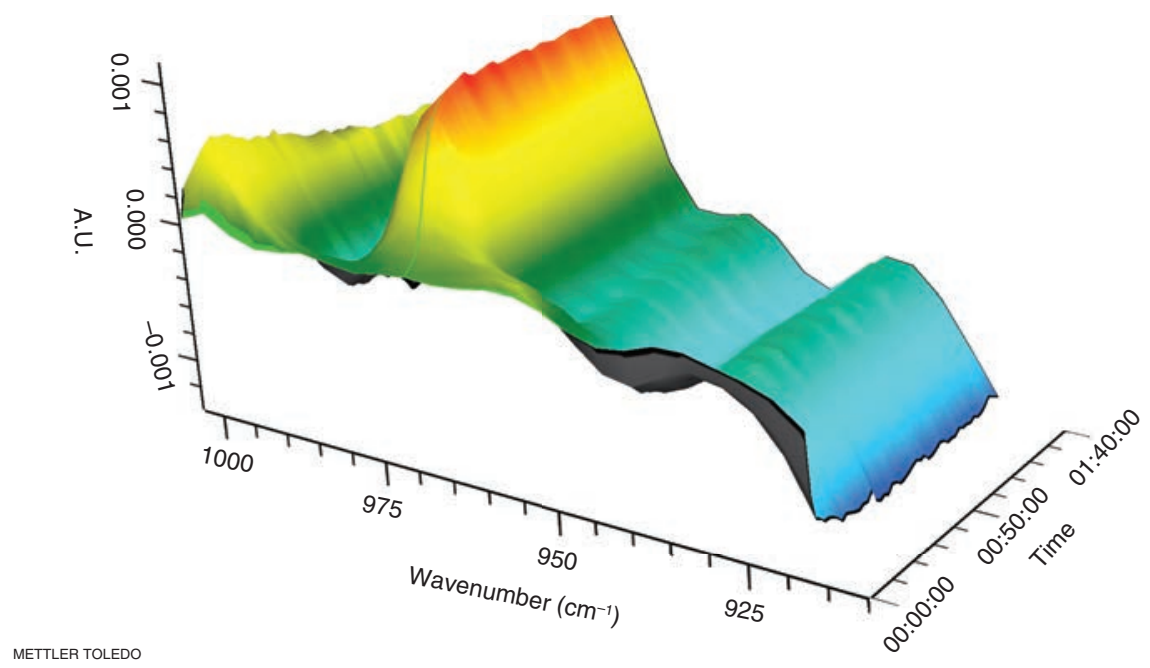

FIGURE 3. 3D-FTIR profiles of the cis-trans isomerization of fat, the reaction was monitored by React IR

TABLE 7. cis-trans Isomerization of different edible vegetable oils

\begin{tabular}{lcccc}
\hline \multirow{2}{*}{ Edible oils } & \multicolumn{3}{c}{ Final isomer composition (\%) } & $\begin{array}{c}\text { Yield of total trans } \\
\text { double bonds (\%) }\end{array}$ \\
\cline { 2 - 4 } Olive oil & Elaidic acid & Trans-linoleic acid & Trans-linolenic acid & $79.2 \pm 0.2$ \\
Camellia seed oil & 79.4 & 78.8 & $/$ & $78.8 \pm 0.9$ \\
Corn oil & 79.3 & 78.0 & $/$ & $78.7 \pm 0.6$ \\
Sesame oil & 79.4 & 78.5 & $/$ & $79.6 \pm 0.7$ \\
Sunflower oil 1\# & 79.7 & 79.8 & $/$ & $78.9 \pm 1.1$ \\
Sunflower oil 2\# & 79.1 & 78.7 & $/$ & $79.0 \pm 0.8$ \\
Soybean oil 1\# & 79.1 & 78.8 & $/$ & $79.3 \pm 1.3$ \\
Soybean oil 2\# & 79.5 & 79.6 & 77.4 & $79.7 \pm 1.0$ \\
\hline
\end{tabular}

Each value in the table represents the mean and mean \pm standard deviation of triplicate analyses, respectively. $1 \#$ and $2 \#$ represent the same variety of edible oils from different manufacturers, respectively. Reaction conditions: reaction temperature $100{ }^{\circ} \mathrm{C}$, reaction time $90 \mathrm{~min}$, ratio of edible oil to catalyst was 250 to $20(\mathrm{w} / \mathrm{w}), \mathrm{N}_{2}$.

acid were all over $79 \%$, and the yields of translinoleic acid fluctuated between $78.0 \%$ and $79.8 \%$. Therefore, nearly $80.0 \%$ yields of TFAs generated in various vegetable oils are an acceptable result for the production of trans-lipids without changing the degree of unsaturation.

\section{CONCLUSIONS}

The cis-trans isomerization of unsaturated fatty acids in edible oils has been successfully developed using simple and cheap $p$-toluenesulfinic acid as catalyst. The effects of reaction time, temperature, catalyst loading, and the amount of water and antioxidants on isomerization have been investigated systematically. Under the optimal conditions, the yield of trans double bonds from isomerized fat could reach $79.6 \%$ without changing either the location of the double bonds or the degree of unsaturation. The results indicated that the amount of water (0-20 wt \%) and antioxidant (0-200 mg/kg) had no significant effect on the cis-trans isomerization of unsaturated fatty acids in edible oils. In addition, this convenient method has been applied to different kinds of vegetable oils and yields of nearly $80.0 \%$ of TFAs were generated, which is a promising result for the production of trans-fats.

\section{ACKNOWLEDGEMENTS}

The authors gratefully acknowledge the financial support from the China Postdoctoral Science Foundation fund project (No. 2017M622364), the Henan Postdoctoral Science Foundation and Basic 
Research Funds in Henan Universities of Henan University of Technology (No. 2015RCJH01).

\section{CONFLICT OF INTEREST}

The authors declare that there is no conflict of interests regarding the publication of this paper.

\section{REFERENCES}

Akin G, Arslan FN, Elmas SNK, Yilmaz I. 2018. Coldpressed pumpkin seed (Cucurbita pepo L.) oils from the central Anatolia region of Turkey: Characterization of phytosterols, squalene, tocols, phenolic acids, carotenoids and fatty acid bioactive compounds. Grasas Aceites 69, e232. https://doi.org/10.3989/gya.0668171

Belitz HD, Grosch W. 1999. Food Chemistry. Springer Verlag. https://doi.org/10.1007/978-3-540-69934-7

Cizmeci M, Musavi A, Kayahan M, Tekin A. 2005. Monitoring of hydrogenation with various catalyst ratios. J. Am. Oil Chem. Soc. 82, 925-929. https://doi.org/10.1007/ s11746-005-1166-3

Duffy PE, Quinn SM, Roche HM, Evans P. 2006. Synthesis of trans-vaccenic acid and cis-9-trans-11-conjugated linoleic acid. Tetrahedron 62, 4838-4843. https://doi.org/10.1016/j. tet.2006.03.006

Elbadawi SMA, Ahmad EEM, Mariod AA, Mathaus B. 2017. Effects of thermal processing on physicochemical properties and oxidative stability of Balanities aegyptiaca kernels and extracted oil. Grasas Aceites 68, e184. https:// doi.org/10.3989/gya.1048162

Farag RS, Elagaimy MAS, Elhakeem BSA. 2010. Effects of mixing canola and palm oils with sunflower oil on the formation of trans fatty acids during frying. Food \& Nutr. Sci. 01, 24-29. https://doi.org/10.4236/fns.2010.11005

Ferreri C, Costantino C, Perrotta L, Landi L, Mulazzani QG, Chatgilialoglu C. 2001. cis-trans Isomerization of polyunsaturated fatty acid residues in phospholipids catalyzed by thiyl radicals. J. Am. Chem. Soc. 123, 44594468. https://doi.org/10.1021/ja0040969

Garcia C, Duby C, Catheline D, Toral PG, Bernard L, Legrand P, Rioux V. 2017. Synthesis of the suspected trans-11, cis13 conjugated linoleic acid isomer in ruminant mammary tissue by FADS3-catalyzed $\triangle 13$-desaturation of vaccenic acid. J. Dairy Sci. 100, 783-796. https://doi.org/10.3168/ jds.2016-11455

Geißler C, Brede O, Reinhardt J. 2003. cis-trans Isomerization of unsaturated fatty acids during $\gamma$-irradiation of barley grains. Radiat. Phys. Chem. 67, 105-113. https://doi. org/10.1016/S0969-806X(03)00003-3

Gibson TW, Strassburger P. 1976. Sulfinic acid catalyzed isomerization of olefins. J Org. Chem. 41, 767-770. https:// doi.org/10.1021/jo00867a009

Hulshof KFAM, Erp-Baart MAV, Antttolainen M, Becker W, Church SM, Couet C, Hermann-KunzE, Kesteloot H, Leth T, Martins I, Moreiras O, Moschandreas J, Pizzoferrato L, Rimestad AH, Thorgeirsdottir H, Amelsvoort JMMV, Aro A, Kafatos AG, Lanzmann-Petithory D, Poppel GV. 1999. Intake of fatty acids in western Europe with emphasis on trans fatty acids: the TRANSFAIR study.
Eur. J. Clin. Nutr. 53, 143-157. https://doi.org/10.1038/ sj.ejcn. 1600692

Iida H, Itoh D, Minowa S, Yanagisawa A, Igarashi A. 2015. Hydrogenation of soybean oil over various platinum catalysts: Effects of support materials on trans fatty acid levels. Catal. Commun. 62, 1-5. https://doi.org/10.1016/j. catcom.2014.12.025

Kala ALA. 2012. cis-, trans- and Saturated fatty acids in selected hydrogenated and refined vegetable oils in the Indian market. J. Am. Oil Chem. Soc. 89, 1813-1821. https://doi. org/10.1007/s11746-012-2086-y

Kuhnt K, Degen C, Jahreis G. 2015. Evaluation of the impact of ruminant trans fatty acids on human health: Important aspects to consider. Crit. Rev. Food Sci. 4, 1964-1980. https://doi.org/10.1080/10408398.2013.808605

Kurt C. 2018. Variation in oil content and fatty acid composition of sesame accessions from different origins. Grasas Aceites 69, e241. https://doi.org/10.3989/gya.0997171

Lemaitre RN, King IB, Mozaffarian D, Sotoodehnia D, Rea TD, Kuller LH, Tracy RP, Siscovick DS. 2006. Plasma phospholipid trans fatty acids, fatal ischemic heart disease and sudden cardiac death in older adults: the cardiovascular health study. Circulation 114, 209-215. https://doi. org/10.1161/CIRCULATIONAHA.106.620336

Li A, Ha YM, Wang F, Li WM, Li QP. 2012. Determination of thermally induced trans-fatty acids in soybean oil by attenuated total reflectance fourier transform infrared spectroscopy and gas chromatography analysis. J. Agric. Food Chem. 60, 10709-10713. https://doi.org/10.1021/ jf3033599

Liu W, Lu GH. 2017. Partial hydrogenation of sunflower oilderived FAMEs catalyzed by the efficient and recyclable palladium nanoparticles in polyethylene glycol. J. Oleo Sci. 66, 1161-1168. https://doi.org/10.5650/jos.ess16206

Mozaffarian D, Katan MB, Ascherio A, Stampfer MJ, Willett WC. 2006. Trans fatty acids and cardiovascular disease. New Engl. J. Med. 354, 1601-1613. https://doi.org/10.1056/ NEJMra054035

Phillips KM, Ruggio DM, Howe JC, Leheska JM, Smith SB, Engle T, Rasor AS, Conley NA. 2010. Preparation and characterization of control materials for the analysis of conjugated linoleic acid and trans-vaccenic acid in beef. Food Res. Int. 43, 2253-2261. https://doi.org/10.1016/j. foodres.2010.06.012

Snyder JM, Scholfield CR. 1982. cis-trans Isomerization of unsaturated fatty acids with $p$-toluenesulfinic acid. $J$. Am. Oil Chem. Soc. 59, 469-470. https://doi.org/10.1007/ BF02636144

Trattner S, Becker W, Wretling S, Öhrvik V, Mattisson I. 2015. Fatty acid composition of Swedish bakery products with emphasis on trans-fatty acids. Food Chem. 175, 423-430. https://doi.org/10.1016/j.foodchem.2014.11.145

Tsuzuki W, Matsuoka A. Ushida K. 2010. Formation of trans fatty acids in edible oils during the frying and heating process. Food Chem. 123, 976-982. https://doi.org/10.1016/ j.foodchem.2010.05.048

Tzeng YZ, Hu CH. 2014. Radical-induced cis-trans isomerization of fatty acids: a theoretical study. J. Phys. Chem. A 118, 4554 4564. https://doi.org/10.1021/jp502434t

Vahmani P, Rolland DC, Gzyl KE, Dugan MER. 2016. Nonconjugated cis/trans, 18:2 in beef fat are mainly $\Delta-9$ desaturation products of trans $-18: 1$ isomers. Lipids 51, 1427-1433. https://doi.org/10.1007/s11745-016-4207-0 